\title{
Assessment of Acetylcholinesterase Inhibition and Anti-inflammatory Activity of Ethanolic Extract of Evolvulus alsinoides Linn.
}

\author{
Garima Jain, Umesh Kumar Patil* \\ Department of Pharmaceutical Sciences, Dr. Harisingh Gour Vishwavidyalaya (A Central University), Sagar, Madhya Pradesh, INDIA.
}

\begin{abstract}
Objectives: The objective of present study is to determine the efficacy of ethanolic extract of Evolvulus alsinoides Linn. for therapeutics at various doses. One more purpose is also to determine anti-inflammatory effects of $E$. alsinoides which are highly associated with CNS disease. Methods: Ethanolic extract of $E$. alsinoides has been used for estimation of acetylcholinesterase inhibitory activity at dose of $100,200,300 \mathrm{mg} / \mathrm{kg}$ on rat. For estimation of acetylcholinesterase, Ellman's method is used which is based on absorbance. Anti-inflammatory activity was evaluated by two in vitro experimental models i.e. heat induced hemolysis and hypotonic solution-induced hemolysis. Results: Ethanolic extract of $E$. alsinoides at the dose of $200 \mathrm{mg} / \mathrm{kg}$ is more effective than 100 and 300 . In heat hemolysis, inflammation was significantly reduced at 50 and $100 \mu \mathrm{g} /$ $\mathrm{ml}$ in EA while hypotonic solution induced inhibition was shown significant at 50,100 and $200 \mu \mathrm{g} / \mathrm{ml}$ in EA. Extract was effective in inhibition of hemolysis in a dose-dependent manner due to its membrane stabilizing
\end{abstract}

action. Thus, E. alsinoides may be employed as alternative and safe drug therapy against inflammation. Conclusion: Several natural products have been used for medicinal purposes in which E. alsinoides is also one of them. It is traditionally claimed for memory enhancement and will help as therapeutics for brain related problems.

Key words: Dementia, Cholinergic, Acetylcholinesterase, Haemolysis, Evolvulus alsinoids.

Correspondence

Prof. Umesh Kumar Patil

Department of Pharmaceutical Sciences, Dr. Harisingh Gour Vishwavidyalaya (A Central University), Sagar-470003, Madhya Pradesh, INDIA.

Phone no: +91-9425172165

Email: umeshpatil29@gmail.com

DOI: 10.5530/ijpi.2021.1.19

\section{INTRODUCTION}

Acetylcholine is a fast-acting neurotransmitter, alters neuronal excitability and coordinates firing of neurons in central area. ${ }^{1} \mathrm{ACh}$ work through pre- and postsynaptic receptors in the brain and contribute to cortical and hippocampal function across phylogeny. ACh is released from nerve terminals in small quantum and extruded by exocytosis. ACh has a very short half-life because acetylcholinesterase (AChE) rapidly hydrolyses $\mathrm{ACh}$ in the terminal of nerve impulse transmission cholinergic synapses. AChE is the most essential enzymes in the family of serine hydrolases. Functions of acetylcholine in learning and memory are already known but now a day it is used in the treatment of CNS disorders like Alzheimer's and Parkinson's disease. ${ }^{2}$ Alzheimer's disease (AD) is well-known neurodegenerative diseases, firstly described and later named by German psychiatrist and pathologist Alois Alzheimer in $1906 .{ }^{3}$ In initial phase of $\mathrm{AD}$, patients decline in cognitive functions and find difficulties even to remember recent events called short-term memory loss while on progression of the disease, patients experience long-term memory loss which includes difficulties in speech, speaking and cognitive thinking etc. and during the late phase language deficits, psychosis, aggressive behavior and depression etc are happened. ${ }^{4,5}$

In 1961 Ellman, Courtney, Andres and Featherston developed a method known as Ellman's method to determination of activity of AChE enzyme. It is quantitative and photometric determination method using extract, homogenates, cell suspensions etc. The enzymatic activity is measured by increase of color produced from thiocholine when it reacts with dithiobisnitrobenzoate ion using spectrophotometer at $412 \mathrm{~nm} .{ }^{6}$

Acetylthiocholine $\stackrel{\text { Enzyme }}{\longrightarrow}$ Thiocholine + Acetate
Thiocholine + Dithiobisnitrobenzoate $\longrightarrow$ Yellow color

It is rapid and sensitive method (i.e. a $10 \mu$ sample of blood is sufficient). Various plants extracts and their active constituents are reported to have anti AD activity. Hypothesis reveals the causes of $\mathrm{AD}$ with their symptoms like dementia, confusion in planning or making decision, poor judgment and withdrawal from work or social activities etc. ${ }^{7,8}$ Studies are strongly correlated the degree of cognitive impairment and a shortage of ACh in patients with AD.

Inflammation is the protective mechanism of the body that consists of several diverse events during any diseases. ${ }^{9}$ Inflammation can be divided into two processes i.e. acute and chronic. It plays vital role in pathogenesis of various diseases like cancer, diabetes, disorder of eye, autoimmune disorder, arthritis, irritable bowel disease and obesity. ${ }^{10}$ Inflammation is also responsible for growth retardation during childhood. ${ }^{11}$ The incidences of inflammation related disease have been increasing continuously. The anti-inflammatory activity of medicinal plants is because of active phytoconstituents present in them. Phenolic compound is generally effective as anti-inflammatory agent because it have ability to inhibit either the production or the action of proinflammatory mediators. ${ }^{12} \mathrm{EA}$ is also a popular Ayurvedic herb used for enhancing memory. ${ }^{13}$ The plant possesses antioxidant, anti-inflammatory, immunomodulaotry and neuroprotective properties. ${ }^{14}$ Evolvulins I and II are the two major active constituents found in EA responsible for different biological activities. ${ }^{15}$ Thus, in the present study ethanol was employed for extraction and evaluation of these compounds against inflammation because in previous study by Nahata et al. experiment was 
performed using ethanolic extract and its fraction on learning behavior and memory enhancing activity. ${ }^{16,17}$

\section{MATERIALS AND METHODS}

\section{Plants material}

E. alsinoides was collected from area adjoining to University campus and authenticated [Bot/H/05/111/01] in the Department of Botany, Dr. Harisingh Gour Vishwavidyalaya, Sagar, (M.P.).

\section{Extraction of E. alsinoides using soxhlet assembly}

The dry herb of E. alsinoides was inserted in a soxhlet apparatus with petroleum ether to defatting purpose then subjected with ethanol (90\%) for $72 \mathrm{hr}$ at $55^{\circ} \mathrm{C}$. The collected extract was concentrated and subjected for study.

\section{Estimation of Total phenolic contents Preparation of drug sample}

$1 \mathrm{ml}$ of extract, $10 \mathrm{ml}$ of water and $1.5 \mathrm{ml}$ of Folin and ciocalteu's reagent (Phenol reagent) were taken in to $25 \mathrm{ml}$ volumetric flask and kept for $5 \mathrm{~min} .4 \mathrm{ml}$ of $20 \% \mathrm{w} / \mathrm{v}$ sodium carbonate solution was added and the volume was made up to $25 \mathrm{ml}$ with double distilled water. The mixture was kept for 30 minutes and then measured the absorbance at $765 \mathrm{~nm}$ using UV-visible spectrometer (Shimadzu, Japan). The total phenolic content was calculated by using gallic acid as standard. ${ }^{18}$

\section{Preparation of Standard solution and standard curve}

$100 \mathrm{mg}$ pure gallic acid was dissolved in $100 \mathrm{ml}$ distilled water. This solution was again diluted with distilled water and prepared aliquots $(100,200,300,400,500,600 \mu \mathrm{g} / \mathrm{ml}) .1 \mathrm{ml}$ of aliquots, $10 \mathrm{ml}$ of water and $1.5 \mathrm{ml}$ of Folin and ciocalteu's reagent (Phenol reagent) were transferred to the $25 \mathrm{ml}$ volumetric flask and kept for $5 \mathrm{~min} .4 \mathrm{ml}$ of $20 \% \mathrm{w} / \mathrm{v}$ sodium carbonate solution was added and the volume was made up to $25 \mathrm{ml}$ with double distilled water. The mixture was kept for 30 minutes and then measured the absorbance at $765 \mathrm{~nm}$ using UV-visible spectrometer (Shimadzu, Japan).

\section{Determination of AChE inhibitory activity Acute toxicity study}

The acute toxicity study was performed as per OECD guidelines 423 . Three animals were selected for each dose group i.e. 5, 50, 300 and 2000 $\mathrm{mg} / \mathrm{kg}$ body weight, given p.o. Different activities of animals (change in fur color, behavior, any lethargic sign, etc.) were observed in the first $4 \mathrm{~h}$ after $10 \mathrm{~h}$ and once a day daily for 14 days.

\section{Experimental animals}

Wistar rats of either sex (150-200g) were selected. They were procured from the animal house of the institute. The experimental protocols were approved by the Institutional animal ethics committee (IAEC No. 379/ GO/ReBi/S/01/CPCSEA, Reference no. 379/CPCSEA/IAEC-2018/035) after scrutinization. The animals were fed with standard pelleted diet and water ad libitum. The animals were acclimatized to the laboratory condition before experiment. The animals were fasted for at least $24 \mathrm{~h}$ before treatment. The animals were divided into 6 group's i.e.

Group 1: Negative control group (0.2\% v/v Tween-80)

Group 2: Positive control group (scopolamine, $0.3 \mathrm{mg} / \mathrm{kg}$; i.p)

Group 3: Standard group (piracetam, $100 \mathrm{mg} / \mathrm{kg}$; oral)

Group 4: Ethanolic extract of EA (100mg/kg)

Group 5: Ethanolic extract of EA (200mg/kg)

Group 6: Ethanolic extract of EA (300mg/kg)
The animals were treated for 15 days, however, scopolamine was administered to the animals on the $9^{\text {th }}$ day, intraperitoneally. ${ }^{17}$

\section{Estimation of AChE inhibitory activity}

The activity was determined through 96 -well microplate assay according to the method of Ellman et al. $1961 .^{7}$ In this method, thiocholine produced by AChE reacts with $5,5^{\prime}$-dithiobis(2-nitrobenzoic acid) (DTNB) to form a colorimetric $(412 \mathrm{~nm})$ product. Acetylthiocholine iodide $(15 \mu \mathrm{M})$ in $25 \mu \mathrm{l}$ was added into a microplate well along with the addition of DTNB $(125 \mu \mathrm{l})$ in $50 \mathrm{mM}$ of Tris/ $\mathrm{HCl}(\mathrm{pH} 8)$ with $\mathrm{NaCl}(0.1$ $\mathrm{M})$ and $\mathrm{MgCl}_{2} \cdot 6 \mathrm{H}_{2} \mathrm{O}(0.02 \mathrm{M})$. Further, $50 \mu \mathrm{l}$ of bovine albumin fraction $\mathrm{V}(0.1 \%), 25 \mu \mathrm{l}$ of test drugs dissolved in methanol and diluted in Tris/ $\mathrm{HCl}(50 \mathrm{mM}, \mathrm{pH} 8)$ at concentrations of 1.25, 12, 20, 40, 80, 160, $320 \mu \mathrm{g} /$ $\mathrm{ml}$ were added into well. The absorbance was measured after 2 min of incubation at room temperature; the initial absorbance was taken at 412 $\mathrm{nm}$ and after $10 \mathrm{~min}$, the final measurement was taken. All the analysis was performed in triplicate. ${ }^{19}$ The AChE activity was calculated using the following formula (Table 1):

AChE Activity (Units $/ \mathrm{L})=\frac{\left(\mathrm{A}_{412}\right) \text { Final- }\left(\mathrm{A}_{412}\right) \text { Initial }}{\left(\mathrm{A}_{412}\right) \text { Calibrator- }\left(\mathrm{A}_{412}\right) \text { Blank }} \times \mathrm{n} \times 200$

$200=$ Equivalent activity $($ Units $/ \mathrm{L})$ of the calibrator when assayed is read at 2 minutes and 10 minutes

$\mathrm{n}=$ dilution factor

$\left(\mathrm{A}_{412}\right)_{\text {Calibrator }}=$ Absorbance of the calibrator at $10 \mathrm{~min}$

$\left(\mathrm{A}_{412}\right)_{\text {Blank }}=$ Absorbance of the blank at $10 \mathrm{~min}$

\section{In vitro anti-inflammatory activity of ethanolic extract of} E. alsinoides

The anti-inflammatory activity of extract was performed using two models i.e Heat-induced haemolysis and hypotonic solution-induced haemolysis. ${ }^{[20]}$

\section{Preparation of Erythrocyte suspension}

It was prepared by collected whole blood followed by washing with normal saline $(0.9 \%, \mathrm{NaCl})$. This volume was adjusted and reconstituted as a $40 \%$, v/v suspension using isotonic buffer solution ( $\mathrm{pH} 7.4$ ). Hemolysis was induced by heat and hypotonic solution to measure the anti-inflammatory activity of test compounds by preventing hemolysis.

\section{Heat-induced hemolysis}

Test compounds were prepared by taking isotonic buffer solution $(5 \mathrm{ml})$ of plants extracts in the concentrations of 50,100,200,300 and $500 \mu \mathrm{g} / \mathrm{ml}$ into two duplicate sets. The vehicle was added to another tube separately as control. The earlier prepared erythrocyte suspension $(30 \mu \mathrm{l})$ of whole blood was added to each tube and mixed gently by inversion. One pair

Table 1: AChE activity of extracts at different dose.

\begin{tabular}{ccc}
\hline Sn & Groups & AChE Activity (Units/L) \\
\hline 01. & Group-1 & $8.550 \pm 0.3041$ \\
02. & Group-2 & $22.91 \pm 0.07339^{* * *}$ \\
03. & Group-3 & $15.17 \pm 0.2962^{* * *}$ \\
04. & Group-4 & $42.70 \pm 1.820^{* * *}$ \\
05. & Group-5 & $66.10 \pm 1.518^{* * *}$ \\
06. & Group-6 & $22.40 \pm 0.982^{* * *}$ \\
\hline
\end{tabular}

Data are represent as mean \pm SEM $(n=6)$ and one-way analysis of variance (ANOVA) followed by Dunnett test for multiple column comparison. ${ }^{*} P<0.01$ and ${ }^{* * *} P<0.001$ were considered to significant compared with control group. 
of the test tube was then incubated at $54^{\circ} \mathrm{C}$ for $20 \mathrm{~min}$. However, another pair was maintained at $0-5^{\circ} \mathrm{C}$ in an ice bath. The reaction mixture was placed for $15 \mathrm{~min}$ and the absorbance was measured at $540 \mathrm{~nm}$ using UV spectrophotometer.

\section{Hypotonic solution-induced hemolysis}

This experiment was performed in duplicate pairs with hypotonic solution. The stock erythrocyte suspension $(30 \mu \mathrm{l})$ was mixed with hypotonic solution $(5 \mathrm{ml})$ of plants extracts in the concentrations of $50,100,200,300$ and $500 \mu \mathrm{g} / \mathrm{ml}$. The vehicle was added to another tube separately as control. This mixture was incubated at $25^{\circ} \mathrm{C}$ for $10 \mathrm{~min}$ and absorbance was measured at $540 \mathrm{~nm}$. The effect of test compounds was calculated as percentage inhibition or acceleration of hemolysis in both tests using following equation:

Percentage acceleration or inhibition of hemolysis $=100 \mathrm{c}\left[10 \frac{\mathrm{OD} 2-\mathrm{OD} 1}{\mathrm{OD} 3-\mathrm{OD} 1}\right]$

Where, OD1 and OD2 was Test samples in isotonic and hypotonic solutions, respectively and OD3 was control sample in hypotonic solution.

\section{Statistical analysis}

Data are represent as mean $\pm \operatorname{SEM}(n=6)$ and one-way analysis of variance (ANOVA) followed by Dunnett test for multiple column comparison. ${ }^{\star} P<0.05,{ }^{*} P<0.01$ and ${ }^{* *} P<0.001$ were considered to be less significant, significant and more significant respectively when all groups were compared with control group.

\section{RESULTS}

Percentage yield of ethanolic extract of EA was $12.68 \%(\mathrm{w} / \mathrm{w})$. Generally AChE activity is raised chronically with the administration of scopolamine. The tested extracts were effective in reducing the activity of AChE in comparison to the control group. Piracetam showed significant activity i.e. 15.17 units/L. Results from Table 1, ethanolic extract of EA reduced the activity of AChE in all doses.

Anti-inflammatory activity was evaluated by selecting two in vitro experiment models i.e. heat induced hemolysis and hypotonic solutioninduced hemolysis. Table 2 shows percentage inhibition of hemolysis by different doses of ethanolic extract of CP and EA. Extracts were showed significant percentage inhibition of hemolysis in dose dependently. Percentage inhibition of ethanolic extract of EA extract was $56.32 \mu \mathrm{g} / \mathrm{ml}$ at the highest dose in heat induced hemolysis model. Percentage inhibition of ethanolic extract of EA extract was $54.79 \mu \mathrm{g} / \mathrm{ml}$ at the highest dose in

Table 2: Percentage inhibition of hemolysis of plants extracts.

\begin{tabular}{cccc}
\hline Treatment & $\begin{array}{c}\text { Concentration } \\
(\mu \mathrm{g} / \mathrm{ml})\end{array}$ & \multicolumn{2}{c}{ Hemolysis inhibition (\%) } \\
\cline { 3 - 4 } & & Heat induced & $\begin{array}{c}\text { Hypotonic } \\
\text { solultion }\end{array}$ \\
\hline Control & - & - & - \\
Standard & 200 & $59.81 \pm 0.7074$ & $76.20 \pm 1.7770$ \\
EA (Ethanolic & 50 & $29.70 \pm 0.4962^{* * *}$ & $32.02 \pm 1.2570^{* * *}$ \\
Extract) & 100 & $35.06 \pm 0.4043^{* * *}$ & $37.68 \pm 0.8655^{* * *}$ \\
& 200 & $45.88 \pm 0.7799^{* *}$ & $42.91 \pm 1.6750^{* * *}$ \\
& 300 & $51.11 \pm 0.4385^{* *}$ & $46.06 \pm 2.1050^{* *}$ \\
& 500 & $56.32 \pm 0.0500^{*}$ & $54.79 \pm 0.9401^{* *}$ \\
\hline
\end{tabular}

Data are represent as mean $\pm \operatorname{SEM}(n=6)$ and one-way analysis of variance (ANOVA) followed by Dunnett test for multiple column comparison. ${ }^{\star} P<0.05$, ${ }^{* *} P<0.01$ and ${ }^{* *} P<0.001$ were considered to be significant when compared with control group.
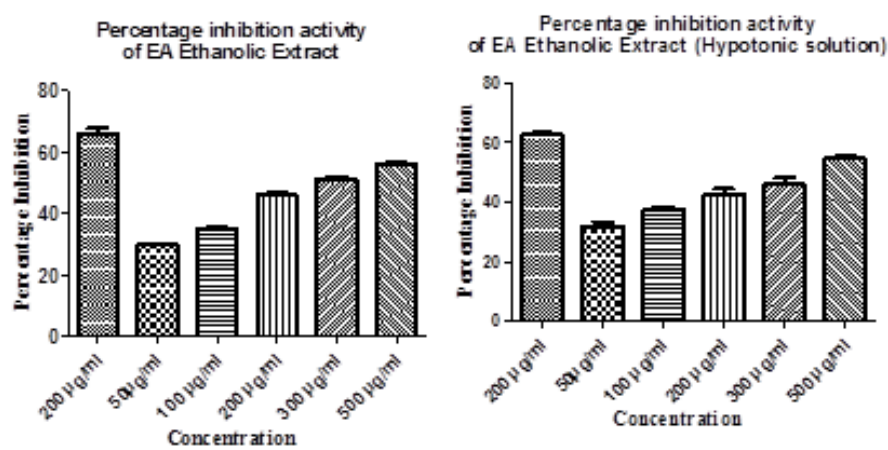

Figure 1: Percentage inhibition of haemolysis of ethanolic extract of EA.

heat induced hemolysis model. The inflammatory activity in the form of heat hemolysis was significantly reduced at 50 and $100 \mu \mathrm{g} / \mathrm{ml}$ while hypotonic solution induced inhibition was shown significant at 50, 100 and $200 \mu \mathrm{g} / \mathrm{ml}$. Extract was effective in inhibition of hemolysis in a dosedependent manner (Figure 1).

\section{DISCUSSION}

The role of ACh is very important in peripheral and central nervous systems both; In peripheral nervous system, it performs the locomotor activity while in central nervous systems, it help in the formation of the memory. In brain, deficiency of ACh or depletion of ACh causes various neurodegenerative diseases in which $\mathrm{AD}$ is one of them. ${ }^{21}$ $\mathrm{AD}$ is an irreversible neurodegenerative disorder primarily targeting elderly populations. ${ }^{22}$ The level of ACh is decrease due to $\mathrm{AChE}$ which affects the cognition and progressed with locomoter disfunctioning. Dementia is major symptom of $\mathrm{AD}$ patients. ACh also affects the locomotor activity due to nicotinic acetylcholine receptors. ${ }^{23,24}$ Rotarod and actophotometer experimental models are used to determine the motor coordination of rodents. This method is sensitive to evaluate cerebellar dysfunction. ${ }^{25,26}$

Inflammation is a biological defense mechanism and secondary response of brain. During inflammation, pro-inflammatory mediators i.e interleukin- $1 \beta$, IL- 6 , IL- 8 are activated. Some other like tumor necrosis factor- $\alpha$, reactive oxygen species, nitric oxide and prostaglandins are also activated. Over production in long time cause degenerative diseases i.e. asthma, cancer, arthritis, atherosclerosis and $\mathrm{AD}$ etc. ${ }^{27}$ Generally plants are the factory of metabolites in which phenolic components play vital role. Phenolic components have multiple activities in which anti-inflammatory activity is very important. They inhibit either the production or the action of proinflammatory mediator. Some other component can up/down regulated transcriptional factors like nuclear factor-KB or Nrf-2 in inflammation and antioxidant pathway. Study reveals that a high intake of phenolic rich food decreased rate of chronic disease such as cardiovascular disease, diabetes, Parkinson disease and $\mathrm{AD}$ etc. ${ }^{28}$

EA is traditionally claimed for memory enhancement. Its activity showed their scavenging properties in brain. However, the EA showed more significant results at $200 \mathrm{mg} / \mathrm{kg}$ in comparison to other doses. Results were found that ethanolic extract of EA were effective in inhibition of hemolysis in both heat induced and hypotonic solution experimental models. The anti-inflammatory activity of plant at various doses shows new criteria for determining the effective dose.

\section{CONCLUSION}

Ethanolic extract of EA showed a protective effect against scopolamineinduced degradation of ACh. Study revealed that extract has anti- 
inflammatory activity which is very important for treatment of neurodegenerative diseases. It can be concluded from the study that EA possess highly significant anti-inflammatory activity in dose of $200 \mathrm{mg} /$ $\mathrm{kg}$ so that it can be used as therapeutics against inflammation in several CNS diseases.

\section{ACKNOWLEDGEMENT}

Authors are thankful to the Sophisticated Instrument Center (SIC), Dr. Harisingh Gour University, Sagar, (M.P.) for sophisticated instrumentation facilities supported under DST-PURSE (II). Financial assistance (SB/ EMEQ-376/2014) received from SERB, DST, Govt. of India is gratefully acknowledged.

\section{CONFLICT OF INTEREST}

The authors declare no Conflict of interest.

\section{REFERENCES}

1. Picciotto MR, Higley MJ, Mineur YS. Acetylcholine as a neuromodulator: Cholinergic signaling shapes nervous system function and behavior. Neuron. 2012;76(1):116-29

2. Zatta $P$, Ibn-Lkhayat-Idrissi $M$, Zambenedetti $P$, Kilyen $M$, Kiss $T$. In vivo and in vitro effects of aluminum on the activity of mouse brain acetylcholinesterase. Brain Res Bull. 2002;59(1):41-5.

3. Bartus RT, Dean RL, Beer B, Lippa S. The cholinergic hypothesis of geriatric memory dysfunction. Science. 1982;217(4558):408-14.

4. Lane CA, Hardy J, Schott JM. Alzheimer's disease. Euro J Neuro. 2018;25(1):5970.

5. Terry AV, Buccafusco JJ. The cholinergic hypothesis of age and alzheimer's disease- related cognitive deficits: Recent challenges and their implications for novel drug development. J Pharmacol Exper Ther. 2003;306(3):821-7.

6. YooKi Y, Park SY. Terpenoids as potential anti-alzheimer's disease therapeutics. Molecules. 2012;17(3):3524-38.

7. Ellman GL, Dian K, Courtney AV, Featherstone RM. A New and rapid colorimetric determination of acetylcholinesterase activity. Biochem Pharmacol. $1961 ; 7(2): 88-95$.

8. Gupta KY, Tate CR. Herbal formulation as memory enhancer in alzheimer condition. United States patent US 7,429,397. 2008;2(12):1-11.

9. Kuprash DV, Nedospasov SA. Molecular and cellular mechanisms of inflammation. Biochemistry. 2016;81(11):1237-9.

10. Arulselvan P, Fard MT, Tan WS, Gothai S, Fakurai S, Norhaian M, et al. Role of antioxidants and natural products in inflammation. Oxid Med Cell Longev. 2016;1-15.

11. Simon D. Inflammation and growth. J Pediatr Gastroenterol Nutr. 2010;51:
S133-4.

12. Kumar GP, Khanum F. Neuroprotective potential of phytochemicals. Pharmacogn Rev. 2012:6(12):81-90

13. Naikawadi VB, Ahire ML, Lahiri A, Nikam TD. In vitro propagation and cell cultures of memory tonic herb Evolvulus alsinoides: A best source for elicited production of scopoletin. Appl Microbiol Biotechnol. 2016;100(8):3463-76.

14. Yadav MK, Singh SK, Singh M, Mishra SS, Singh AK, Tripathi JS, et al. In vivo toxicity study of ethanolic extracts of Evolvulus alsinoides and Centella asiatica in swiss albino mice. Macedonian J Med Sci. 2019;7(7):1059-76.

15. Fan BY, LuY, Yang M, Li JL, Chen GT. Evolvulins I and II, resin glycosides with a trihydroxy aglycone unit from Evolvulus alsinoides. Org Let. 2019;21(16):654851.

16. Nahata A, Patil UK, Dixit VK. Effect of Convulvulus pluricaulis Choisy. on learning behaviour and memory enhancement activity in rodents. Nat Prod Res. 2008:22(16):1472-8.

17. Nahata A, Patil UK, Dixit VK. Effect of Evolvulus alsinoides linn. on learning behavior and memory enhancement activity in rodents. Phytother Res. 2010;24(4):486-93.

18. Anandjiwala S, Bagul MS, Parabia M, Rajani M. Evaluation of free radical scavenging activity of an ayurvedic formulation, panchvalkala. Indian J Pharm Sci. 2008;70(1):31-5.

19. Topcu G, Kolak U, Ozturk M, Boga M, Hatipoglu SD, Bahadori F, et al. Investigation of anticholinesterase activity of a series of salvia extracts and the constituents of Salvia staminea. Nat Prod J. 2013;3(1):3-9.

20. Shinde UA, Phadke AS, Nair AM, Mungantiwar AA, Dikshit VJ, Saraf MN Studies on the anti-inflammatory and analgesic activity of Cedrus deodara (Roxb.) Loud. wood oil. J Ethnopharmacol. 1999;65(1):21-7.

21. Kamens HM, Peck C, Garrity C, A Gechlik, Jenkins BC, Rajan A. $\alpha 6 \beta 2$ nicotinic acetylcholine receptors influence locomotor activity and ethanol consumption. Alcohol. 2017;61:43-9.

22. Rabiei Z, Setorki M. Effect of hydroalcoholic Echium amoenum extract on scopolamine-induced learning and memory impairment in rats. Pharmaceu Biol. 2018;56(1):672-7.

23. Hasegawa $Y$, Inoue T, Kawaminami S, Fujita M. Effects of scallop shell extract on scopolamine-induced memory impairment and MK801-induced locomotor activity. Asian Pac J Trop Med. 2016;9(7):662-7.

24. Winnicka K, Tomasiak M, Bielawska A. Piracetam-an old drug with novel properties?. Acta Poloniae Pharmaceutica. 2005;62(5):405-9.

25. Shiotsuki $H$, Yoshimi $K$, Shimo $Y$. A rotarod test for evaluation of motor skill learning. J Neurosci Meth. 2010;189(2):180-5.

26. Mirza R, Sharma B. Selective modulator of peroxisome proliferator-activated receptor- $\alpha$ protects propionic acid induced autism-like phenotypes in rats. Life Science. 2018;214:106-17.

27. J Rogers. The inflammatory response in alzheimer's disease. J Periodont. 2008:79(85):1535-43.

28. Ambriz-perez DL, Leyva-lopez N, Gutierrez-grijalva EP, Heredia JB. Phenolic compounds: Natural alternative in inflammation treatment. Cogent Food Agric 2016;2(1):1-14.

Article History: Submission Date : 01-12-2020; Revised Date : 23-12-2020; Acceptance Date : 31-01-2021

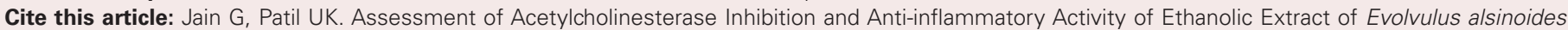
Linn. Int. J. Pharm. Investigation. 2021;11(1):104-7. 